\title{
Strangling by Design; The Tragedy of Small Scale Farmers in Kenya
}

\author{
Joram Ngugi Kamau \\ Department of Agricultural Economics Egerton University-Kenya
}

\begin{abstract}
How to cite this paper: Kamau, J.N. (2019) Strangling by Design; The Tragedy of Small Scale Farmers in Kenya. International Journal of Food Science and Agriculture, 3(3), 253-256.
\end{abstract}

DOI: $10.26855 /$ ijfsa.2019.09.015

*Corresponding author: Joram Ngugi Kamau, Department of Agricultural Economics Egerton University-Kenya.

Email: ngugij88@gmail.com

\begin{abstract}
The agrarian economy in Kenya is characterized by diminutive benefits by most small scale farmers from the agricultural supply chain due to the venomous gluttony of the most central actors in the value chain. Small scale farmers are positioned as net losers in the whole agricultural value chain but can't quit for survival reasons. While this is the reality in the country, small scale farmers find themselves in a quagmire of choosing their marauder; brokers or the government. The former is ruthless while the latter is a smokescreen. The study used descriptive statistics using SPSS software to depict the insatiable appetite by the middlemen and government captors who frustrates the agrarian economy in the country. There are no standardized metric measures that guide the buying of agricultural commodities at the farm gate by the middle men. Prices are malevolently dictated by the brokers where the farmers have to swallow the bitter pills due to their economic detriments. The government on the other hand makes payments at their own pace without considering the economic survival of the farmers. Time value for money is not a factor in government's institutions and breach of contracts has been a norm. For a country that aspires to be food secure, the import mentality of agricultural produces by 'tenderpreneurs' must be dismantled from the onset. Frustrating local production to pave way for the lucrative import business is a mistake that no nation can afford to commit especially if it's the only sector it has a comparative advantage in.
\end{abstract}

\section{Keywords}

Small scale farmers; Value chain; Net losers

\section{Introduction}

Kenya has a comparative advantage in agricultural production due to favorable climatic and ecological conditions but keeps mutilating this phenomenon by frustrating small scale farmers. The reason behind this is so that the high profile economic and political buccaneers can benefit from the import industry at the expense of local producers. They choked the pyrethrum, sisal, cotton, sugarcane and a myriad of other products so that they can make money from the import industry and dominate the entire supply chains (Wekesa et al., 2015). Lipton, (2005) defined small scale farmers as those with a low asset base, operating less than 2 hectares of cropland and where farmers tend to practice a mix commercial and subsistence mode of production.

Production in Kenya is marred by inconceivable cost of production where the tax man finds a lazy hotspot to get revenue since the farmers must produce solely for their consumption. Farm inputs are highly taxed from the raw materials to the final inputs (Odero, 2017). The trickle effect of this is that the input prices have an exponentially exaggerated cost. But why don't they quit? They have to produce for their domestic consumption; otherwise the cartels would be smiling to the banks in the name of food aids and rationed imports.

Manufacturers of agrochemicals and farm inputs in the country are another nightmare to the small-scale farmers (Gyau 
et al., 2016). How they arrive at their pricing decisions is always questionable. They only have two explanations at their disposal; high taxation of raw materials and the cost of electricity in the country (Bolo, 2016). Their inefficiencies and vilest production techniques is recovered from the languishing farmers. They don't want to invest in modern production techniques which are cost effective since the burden of their archaic production techniques will be swiftly transferred to the vulnerable farmers.

While the government crows for a food secure country, little investment is done in the agricultural extension services. Farmers are left with trial and error production methods and have no idea on when to produce, how to produce and what to produce in their ecological zones. The weather man in the country factually assists in forecasting day and night for the farmers and therefore farmers are left to gamble with their production. Crop failures due to pest, diseases and weather related issues have been the norm in a country where $70 \%$ of its populace depends on agriculture either directly or indirectly (Mathenge et al., 2015).

Post-harvesting losses in the country account for $30 \%$ of total agricultural outputs. This is occasioned by lack of knowhow in handling agricultural products (Suleiman and Kurt, 2015). Designed coordination gap in the supply chain ensures that the surplus production is at the disposal of the central actors in the value chain. With poor or no storage facilities for the farm surpluses, middlemen and the government decoys pop out to strangle the ailing farmers.

Marketing of agricultural produces is a stage in the value chain that torments the small scale farmers to agony, pain and despair. From the land preparation to harvesting, farmers are at their own struggles but immediately find unremorseful brothers at the marketing stage who seal their perpetual grousing. There are limited standardized measures of agricultural products such as metric measures at the farm gate where agricultural commodities are subjective to the misnomer of the agrarian scavengers.

\section{Methodology}

The study was conducted in Nakuru County in Kenya. This area was purposively selected due to the abundance of maize production from the area. Maize and maize products are literally consumed by every household in the country on a daily basis. The study randomly sampled 100 small scale farmers from which inferences were drawn for the whole population.

\section{Results and Discussions}

The table below describes the distribution of marketing channels and the prices offered by each channel. The study identified three marketing channels namely; self-marketing, middlemen and the government. Middlemen offered a variation in prices ranging from Ksh.1100 to Ksh.2000 while self-marketing and the government offered a fixed price of Ksh.2000 and Ksh.2600 respectively on a $90 \mathrm{Kg}$ bag of maize.

Table1. Various Marketing Channels

MARKETING_CHANNEL * PRICE_90KG_BAG CROSSTABULATION

\begin{tabular}{lcccccccccc}
\hline & \multicolumn{1}{c}{ PRICE_90KG_BAG (KSH) } & Total \\
\cline { 2 - 8 } MARKETING_CHANNEL & $\mathbf{1 1 0 0}$ & $\mathbf{1 2 0 0}$ & $\mathbf{1 3 0 0}$ & $\mathbf{1 4 0 0}$ & $\mathbf{1 5 0 0}$ & $\mathbf{1 6 0 0}$ & $\mathbf{1 7 0 0}$ & $\mathbf{2 0 0 0}$ & $\mathbf{2 6 0 0}$ & \\
\hline SELF MARKETING & 0 & 0 & 0 & 0 & 0 & 0 & 0 & 39 & 0 & 39 \\
MIDDLEMEN & 1 & 3 & 3 & 8 & 7 & 4 & 1 & 0 & 0 & 27 \\
GOVERNMENT & 0 & 0 & 0 & 0 & 0 & 0 & 0 & 0 & 34 & 34 \\
Total & 1 & 3 & 3 & 8 & 7 & 4 & 1 & 39 & 34 & 100 \\
\hline
\end{tabular}

The 3D graph below presents the three marketing channels identified by the study and their respective duration of payment to the farmers. While middlemen are offering an instant payment, their prices are so varied begging the question of integrity in their business. On the other hand, conducting business with the government seems lucrative at the face value but in reality, it's a source of agony and regret among farmers and fellow citizens in the country. 
While agriculture ought to be a pull factor to the unemployed in the country, no rational individual will venture into this business when all they see are deprived farmers surrounded by a cohort of flamboyant government captors and middlemen who thrive solely by sucking the bona fide efforts of these miserably living farmers. The consequence of this is that food security in the country will remain a mirage as long as the beneficiaries of the agrarian economy is skewed towards few individuals in the agricultural supply chain as indicated by the results.

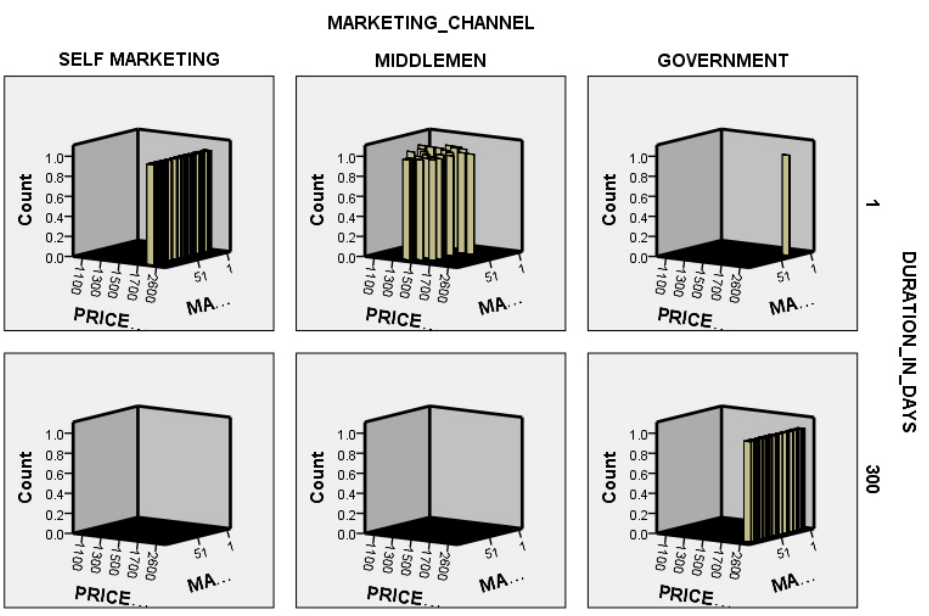

Figure 1. Marketing Channels and Payment Durations

While self-marketing and middlemen provides money to the farmers within $24 \mathrm{hrs}$ of transaction, government payment to the farmers takes up to 300 days (ten months) to be effected as indicated in the table below.

Table 2. Marketing_Channel * Duration_In_Days Crosstabulation

\begin{tabular}{lccc}
\hline & \multicolumn{2}{c}{ DURATION_IN_DAYS } & Total \\
\cline { 2 - 3 } MARKETING_CHANNEL & $\mathbf{1}$ & $\mathbf{3 0 0}$ & 39 \\
\hline SELF MARKETING & 39 & 0 & 27 \\
MIDDLEMEN & 27 & 0 & 34 \\
GOVERNMENT & 0 & 34 & 100 \\
Total & 67 & 34 & \\
\hline
\end{tabular}

With the bleating financial constrain by small scale farmers, whose majorities' sole source of income is farming, manipulation by the middle men is inevitable. They take advantage of their financial urgency to exploit them and leave them to the mercies of the government. Due to the treacherous nature of feeder roads in the country's rural areas, very few have the ability to afford means of transport to the local markets.

Small scale farmers who are unable to withstand the torture of the middle men and are unable to market on their own find refuge in the government where time value for money is not a factor. These impoverished farmers stay for months without receipt of any coin despite their delivery due to the price bait. Officials in the government institutions keeps these farmers on the waiting bay in the pretext of payment processing which take months to see the light of the day.

\section{Conclusion and Recommendations}

Small scale farmers in the country are victims of their hard work. As demonstrated by the study, market access by the farmers has been a scavenging avenue for exploitation and abuse. One key issue noted during the study is that middle men and brokers are notorious in the sense that they have a complete disregard of standardized metric measures when 
purchasing agricultural products at the farm gate. Due to the economic and infrastructural disadvantage exhibited by small scale farmers in the country, middle men dictate the prices at the farm gate creating a double tragedy in terms of pricing and quantification.

With government institutions whose moral and ethical integrity is beyond restoration, the captors prolong the payment duration for farmers as indicated by the study. If there is no return on investment, any rational producer quit or reduces the quantity produced. Wh en the market for agricultural products becomes the cash cow for economic buccaneers in the country at the expense of the languishing farmers, the ultimate outcome is a vicious cycle of food insecurity in the country.

Due to inefficiencies in government institutions, the government should fully quit from transacting business with the farmers. Doing business with the Kenyan government in all sectors has been marred by cartels that not only ensure that the initial engagement is corrupt, but also diverts the payments for months and even years to their personal investments. Payments are later made in piecemeal that really discourage any engagement with any government institution. In light of this, the author unequivocally recommends for legislation that upon successful transaction with the government, and failure to pay within 30 days, any document substantiating the existence of a contract should automatically become a legal tender to the extent of the amount owed. In this case, the document can be presented to any bank for money without notification upon the lapse of the 30 days window. It has become a norm on the part of the government to breach contracts with individuals without any rational consideration of the economic inconveniences they cause.

To curb the malice by middle men, farmers should embrace cooperative movements where they can inculcate elements such as value addition and cold storage in the value chain. By marketing in bulk, farmers will enjoy benefits of economies of scale and therefore evade the manipulation by these perennial brigands whose only motive is to propagate the selfish culture of unbounded capitalism that has drained off the country's coffers.

While this policy document finds its way into the archives to gather dust, it's imperative that the government invests heavily on addressing the endemic dragon of corruption, appetite for the lucrative government tenders, impunity and abuse of office in government institutions. Rewards to factors of production must be realized with an underscore on the marginal productivity of each factor of production as opposed to the scramble for government tenders in the brewing democratic republic of impunity.

\section{References}

[1] Bolo, M. (2016). Innovation systems and capability building among smallholders: lessons and insights from kenya's flower farmers. Innovation Systems: Towards Effective Strategies in support of Smallholder Farmers, 74.

[2] Gyau, A., Mbugua, M., \& Oduol, J. (2016). Determinants of participation and intensity of participation in collective action: evidence from smallholder avocado farmers in Kenya. Journal on Chain and Network Science, 16(2), 147-156.

[3] Lipton, M. (2005) Crop science, poverty, and the family farm in a globalizing world. 2020 Discussion paper 40. International Food Policy Research Institute, Washington DC

[4] Mathenge, M. K., Smale, M., \& Tschirley, D. (2015). Off - farm employment and input intensification among smallholder maize farmers in Kenya. Journal of Agricultural Economics, 66(2), 519-536.

[5] Odero-Waitituh, J. A. (2017). Smallholder dairy production in Kenya; a review. Livestock Research for Rural Development, 29(7).

[6] Suleiman, R. A., \& Kurt, R. A. (2015). Current maize production, postharvest losses and the risk of mycotoxins contamination in Tanzania. In 2015 ASABE Annual International Meeting (p. 1). American Society of Agricultural and Biological Engineers.

[7] Wekesa, R., Onguso, J. M., Nyende, B. A., \& Wamocho, L. S. (2015). Sugarcane In Vitro Culture Technology: Applications for Kenya's Sugar Industry. Journal of Biology, Agriculture and Healthcare, 5(17), $127-134$. 